\title{
PRÁTICAS DECOLONIAIS EM EDUCAÇÃO A PARTIR DE UMA EDUCAÇÃO CENTRADA EM ESTUDANTES
}

\author{
DECOLONIAL PRACTICES BASED ON STUDENT-CENTERED \\ EDUCATION
}

\author{
Juliana Crespo Lopes \\ Doutora, Universidade de Brasília - UnB \\ Brasília, DF - Brasil \\ juliana.jcl@gmail.com \\ Fernanda Fochi Nogueira Insfran \\ Doutora, Universidade Federal Fluminense - UFF \\ Rio de Janeiro, RJ- Brasil \\ fernanda_insfran@id.uff.br \\ Lúcia Helena Cavasin Zabotto Pulino \\ Doutora, Universidade de Brasília - UnB \\ Brasília, DF - Brasil \\ luciahelenaczp@gmail.com
}

\begin{abstract}
Resumo: Este artigo objetiva traçar possibilidades de uma releitura latino-americana decolonial das teorias e posturas educacionais fundamentadas na Abordagem Centrada na Pessoa (ACP) - pensada aqui enquanto um modelo epistemológico da psicologia para práticas educativas. Por ser uma abordagem que valoriza as interações de pessoa para pessoa, a ACP trouxe a possibilidade de pensarmos uma aprendizagem verdadeiramente significativa porque é focada nos interesses genuínos dos alunos. Portanto, pressupõe relações não opressivas, mais democráticas e que valorizam os saberes tradicionais oriundos da nossa história oral, que transcendem a hegemonia eurocentrada e do Norte. Assim, apresentamos os principais pressupostos da ACP e suas aplicações na educação - o que chamamos de Educação Centrada em Estudantes, a partir do que vem sendo discutido e desenvolvido por autores latino americanos da psicologia e da educação. Consideramos ser esta abordagem uma colaboração para a construção de uma dinâmica pedagógica decolonial. Então, realizamos uma reflexão teórica que nos suscitou uma profícua articulação entre as duas epistemologias presentes neste trabalho: a ACP latino-americana e a perspectiva do Sul global sobre educação. Juntas, acreditamos que elas podem ajudar na consolidação de práticas educacionais libertárias, democráticas e decolonizadas.
\end{abstract}

Palavras chave: Abordagem centrada na pessoa. Decolonialidade. Práticas educativas.

\begin{abstract}
This article proposes to outline the possibilities of a decolonial Latin American rereading of educational theories and postures based on the Person-Centered Approach (PCA) - taken here as an epistemological model of psychology for educational practices. Because it is an approach that values interactions from person to person, the PCA has brought the possibility of thinking about truly meaningful learning because it is focused on the genuine interests of the students, therefore it presupposes non-oppressive and more democratic relations that value the traditional knowledge coming from our oral history, which transcend the Eurocentred and Northern hegemony. Thus, we present the main assumptions of PCA and its applications to education - what we call Student Centered Education, from what has been discussed and developed by Latin American authors of psychology and education. We understand that this approach can contribute to build a decolonial pedagogical dynamic. Therefore, we conducted a theoretical reflection here that raised us to a fruitful articulation between the two epistemologies presented here: the Latin American CPA and the Global south perspective on education. We believe that together they can help consolidate libertarian, democratic and decolonial educational practices.
\end{abstract}

Keywords: Person-centred approach. Decolonialism. Pedagogical practices.

Para citar - (ABNT NBR 6023:2018)

LOPES, Juliana Crespo; INSFRAN, Fernanda Fochi Nogueira; PULINO, Lúcia Helena Cavasin Zabotto. Práticas decoloniais em educação a partir de uma educação centrada em estudantes. Eccos - Revista Cientifica, São Paulo, n. 54, p. 1-15, e17029, jul./set. 2020. Disponível em: https://doi.org/10.5585/eccos.n54.17029. 


\section{Introdução}

Fazer uma releitura decolonial latino-americana dos pressupostos da Abordagem Centrada na Pessoa (ACP) aplicados à educação foi um instigante desafio. Por mais que a ACP tenha revolucionado as teorias e práticas psicoterápicas - ousando romper com a relação hierárquica entre terapeuta e paciente e propondo uma relação de pessoa para pessoa - e trazido importantes contribuições para pensarmos as relações educativas e demais relações sociais, seu desenvolvimento se deu em tempos em que a lógica colonial e capitalista imperavam e não havia espaço e oportunidade para que grupos colonizados - os povos do Sul global - escapassem aos modelos epistêmicos do Norte, impostos a nós via cultura, ciência, arte, linguagem, símbolos e signos em geral.

Assim, apesar de nos depararmos com uma linguagem e lógica que, dentro de uma perspectiva decolonial, deveria ser refutada, consideramos relevante nos apropriarmos das contribuições da ACP para a educação (ROGERS, 1985), que em diálogo com teóricos do Sul, colabora para uma educação libertária, democrática e decolonizada.

Consideramos necessário, para respaldar a proposta aqui apresentada, que nos apresentemos enquanto mulheres latino-americanas, porquanto se propor a falar sobre decolonialidade é bastante delicado por sermos de um contexto socioeconômico de privilé gios e lidas como brancas. Porém, além de sermos oriundas do Sul do mundo, nos identifica mos com a decolonialidade como educadoras. E é nesse recorte, pensando especificamente em uma educação formal em todos os níveis, que propomos uma prática de construções coletivas de conhecimentos e afetos.

\section{A abordagem centrada na pessoa e suas contribuições à educação centrada em estudantes}

Apesar de ser mais reconhecida enquanto abordagem clínica, a ACP trouxe contribuições valiosas à área de Educação por buscar deslocar o centro do ensino dos conteúdos/conhecimentos do professor para a aprendizagem significativa do aluno (ROGERS, 1985). A ACP difere de outras correntes da psicologia moderna, como o behaviorismo e a psicanálise, por exemplo, por situar-se em outro paradigma de entendimento da pessoa em suas relações com o mundo: o paradigma fenomenológico, o qual valoriza a experiência subjetiva e consciente, surgindo, portanto, como método para lidar com o aspecto existencial do processo terapêutico (SPIELBERG, 1972).

$\mathrm{O}$ enfoque da psicologia humanista reside na liberdade, responsabilidade e intencionalidade vistas como características intrínsecas à condição humana. Privilegia-se a consciência e a vivência do momento presente e enfatiza-se o enfoque fenomenológico e compreensivo, ou seja, valoriza-se a experiência subjetiva e consciente e a compreensão por empatia, em contrapartida, à explicação causal exterior. A psicologia humanista está comprometida com mudanças sociais e culturais na construção de uma sociedade mais humana, menos controladora e com relações pessoais pautadas na abertura e na autenticidade. Tais características possibilitam vivências auto-expressivas e prazerosas (BOAINAIN, 1998). 
Assim, entendemos que a ACP propõe uma mudança de paradigma não só na relação terapeuta-cliente, mas em todas as relações sociais, inclusive em pequenos e grandes grupos. Tal fato se dá porque esta abordagem tem como pressupostos a Compreensão Empática, a Consideração Positiva Incondicional, a Autenticidade na relação e a Tendência Atualizante. Os três primeiros são as condições inerentes a um clima facilitador de crescimento que, no caso educacional, devem estar presentes na relação entre docentes e discentes.

A compreensão empática é a capacidade de colocar-se no lugar do outro, ajudando-o a perceber que está sendo compreendido e respeitado, mesmo que haja uma gama de diferenças entre as pessoas envolvidas na relação. A diferença entre as pessoas é valorizada na Abordagem Centrada na Pessoa, pois ser o que se é implica em saúde, no sentido de não se deixar guiar por um outro referencial que não o da sua própria avaliação enquanto sujeito livre. A compreensão empática se configura enquanto uma abertura e valorização do outro, da alteridade, do múltiplo.

A Consideração Positiva Incondicional consiste em considerar a pessoa como um todo, sem submetê-la a qualquer tipo de julgamento de valores sociais, para que esta possa experimentar-se livremente, sem qualquer empecilho ou bloqueio de sua consciência aos seus sentimentos ou atitudes (ROGERS \& WOOD, 1974). Já a atitude de autenticidade (ou congruência) nas relações é explicada por Rogers e Wood (1974) da seguinte maneira:

Não significa que eu externe impulsivamente quaisquer sentimentos que eu experimente. (...) O que eu disser ao meu paciente não deverá contradizer o que eu estiver sentindo com relação a ele. (...) Minha postura sem defesas, minha autenticidade, é ess encial para estabelecer e manter vivo um relacionamento confiante (p. 206).

A partir da Tendência Atualizante, entende-se ser natural a todos os sujeitos a busca e o aprimoramento do seu desenvolvimento (ROGERS \& ROSENBERG, 1997). Assim, de acordo com esses autores, todas as pessoas têm potencial e iniciativa de crescimento, independente de raça, gênero, geolocalização ou qualquer outro determinante. Em contextos que dispõem de condições facilitadoras de crescimento, a Tendência Atualizante ganha mais força, justamente por existir um clima facilitador que, ao invés de oprimir e silenciar, acolhe, ouve e dá espaço para o crescimento e, no contexto educacional, para a construção de conhecimentos e a aprendizagem significativa.

Para a ACP, o centro da educação deve ser deslocado dos conteúdos para o interesse genuíno do aluno. Cunhou-se assim o termo "ensino centrado no aluno", um modelo democrático de educação em que o papel do professor passou a ser o de facilitador da aprendizagem significativa. Esta aprendizagem é auto-iniciada e avaliada pelo próprio estudante, tendo como essência a significação. Assim, a aprendizagem seria algo experiencial, 
advinda da vivência do aprendiz, contemplando todas as dimensões da vida desse e não só a dimensão cognitiva, que é privilegiada pela educação convencional. Existe uma diferença entre aprendizagem significativa e a chamada aprendizagem teórica. $\mathrm{Na}$ teórica, o aprendiz é instruído a fazer ou assimilar algo sem maior compreensão (ROGERS, 1985). O aluno não vivencia ou significa aquele conhecimento que está aprendendo na prática.

Propomos aqui a compreensão de Educação Centrada em Estudantes (ECE) enquanto uma prática educativa que, por meio da aprendizagem significativa e de todas as atitudes facilitadoras da ACP, promoveria rachaduras nos modos de ser e fazer nos espaços educacionais, promovendo transformações de posturas individuais, coletivas e estruturais. Utilizaremos aqui o termo Educação ao invés de Ensino, por entendermos que a proposta defendida como prática decolonial precisa demonstrar, já na sua denominação, a abrangência pretendida: ser um paradigma educacional de relações mais humanas, democráticas e, portanto, despido do autoritarismo tão comumente empregado nas relações educativas convencionais.

\section{Decolonialidade e educação decolonial}

Tem-se, atualmente, uma macroestrutura global pautada pela dominação/exploração econômica, cultural, social, étnica de determinados países/povos sobre outros, onde persiste um padrão mundial de poder que colabora para a manutenção do sistema de produção capitalista e todas as suas afluências. Em resposta a essa colonialidade do poder surgem os estudos voltados a uma perspectiva decolonial, entendendo que se fazia necessário promover práticas e saberes partindo de outras visões de mundo e cosmologias.

Especificamente, em relação à educação e cultura, o paradigma colonial promoveu uma dominação epistemológica a partir da sustentação de que um pequeno grupo de países dominantes pautasse sua visão de mundo, suas verdades e suas realidades para os demais, constituindo aí um privilégio epistêmico o qual privilegia projetos imperiais, coloniais e patriarcais (GROSFOGUEL, 2016). O autor explica que, para a manutenção do paradigma colonial, instaurou-se uma ideia de inferioridade epistêmica. Grosfoguel defende que, desde o século XV, com a expansão europeia, ocorre um epistemicídio de povos e culturas das regiões colonizadas. Portanto, não é possível falar de decolonialidade sem nos remetermos ao colonialismo que tanto oprimiu e oprime os povos das culturas colonizadas pelas potências hegemônicas ao longo de vários séculos na História Ocidental. Tal discussão, iniciada nos estudos históricos e sociológicos, recentemente ganhou espaço nos campos da educação e da 
psicologia. Áreas que majoritariamente fundamentavam a compreensão dos fenômenos nas ciências e paradigmas colonizadores e eurocêntricos.

A partir da discussão acerca da preterição de certos conhecimentos a favor de outros, mais respaldados pela epistemologia eurocêntrica, encontramos a importância de uma produção de conhecimentos própria, protagonizada por sujeitos, coletivos e comunidades subalterizadas, a que Mignolo (2003) chama de diferença colonial. Nessa resposta ao privilégio epistêmico imposto, realiza-se um giro decolonial, constituindo-se como abertura e liberdade para outros pensamentos e outras práticas possíveis para o ser, o saber, a economia, a política e outros elementos constituintes das sociedades (MIGNOLO, 2008).

A nomenclatura decolonial no lugar de descolonial se dá por haver um entendimento de que o prefixo "des" está relacionado apenas a uma recusa/denúncia de um modelo educacional enquanto que o prefixo "de" marca uma propositividade para além das concepções hegemônicas de transmissão do saber, sendo a práxis de uma insurgência educativa propositiva (OLIVEIRA, 2016). Tal entendimento envolve diferentes sujeitos e coletivos para a construção de novos saberes e novas possibilidades de se realizar a produção, articulação e divulgação desses saberes. Mais do que um projeto acadêmico, a decolonialidade é uma prática de oposição e intervenção contra-hegemônica, rompendo binarismos e promovendo uma diversidade epistêmica (BERNARDINO-COSTA \& GROSFOGUEL, 2016).

O pensamento decolonial tem suas origens latinoamericanas nas cosmologias dos povos tradicionais e parte disso para defender práticas de produção de conhecimentos distantes de paradigmas cartesianos, positivistas, euro e estadunidense-centrados. Porém, percebemos a importância de, para além disso, problematizar a forma como as relações de poder e as relações de privilégio e inferioridade epistêmica estão presentes nas práticas educacionais de nossa sociedade. Nesse contexto, os estudantes são entendidos como sujeitos desprovidos de conhecimentos e que devem se subjugar ao domínio docente que é, afinal, domínio da cultura e epistemologia dominantes.

Pensando na importância da diversidade epistêmica, problematizamos a Educação Centrada em Estudantes enquanto postura e prática pedagógica que podem colaborar em prol de uma pedagogia decolonial.

No cuidado de estarmos de acordo com o viés ideológico de uma produção científica que busque quebras na estrutura colonial do conhecimento, destacamos três questões que serão devidamente abordadas neste trabalho: a) Rogers superou a compreensão de não-diretividade, presente no início da sua obra, que foi bastante criticada por ser concebida enquanto prática liberal (LIBÂNEO, 2005); b) ainda que a ACP tenha sido formulada por um homem cis, 
heterossexual, branco e estadunidense, a partir da década de 1970, a ACP passa a ser fortemente desenvolvida e estimulada como teoria e prática na psicologia latinoamericana e especificamente brasileira; c) a proposta da ECE é uma forma de romper com o modelo de educação convencional, autoritário, centrado em conteúdos e voltado para uma formação mercadológica, inclusive se aproximando de algumas práticas e posturas decoloniais.

\title{
O extrapolamento do conceito de não-diretividade na ACP
}

Críticas a respeito da proposta de Carl Rogers para uma Educação Centrada em Estudantes são encontradas na literatura (LIBÂNEO, 2005; BECKER, 2016). Duas principa is críticas têm sido (1) a afirmação de que não seria de fato democrática, por não considerar um viés de classe; e (2) em relação à denominação "não-diretiva".

Em relação a defesa de práticas democráticas, em 1977 - Ditadura Militar no Brasil e em vários países latinoamericanos -, Carl Rogers esteve no Brasil e, ao ser questionado em uma entrevista a uma revista sobre as possibilidades de repercussão da ACP para a democracia no mundo, respondeu:

\begin{abstract}
Nos Estados Unidos, a psicologia acadêmica poderia dar excelente aconselhamento e ajuda a governos ditatoriais. Acho que, se qualquer autoridade diz 'queremos que as pessoas sejam mudadas desta forma', a psicologia acadêmica sabe muito bem como mudar as pessoas, gradualmente, no sentido que se quiser. Evejo is so como um grande perigo. A psicologia humanista seria uma valiosa conselheira a uma forma de governo democrático, pois ela o ajudaria a ser cada vez mais democrático, a compreender as capacidades, os direitos e a habilidade do cidadão de ser res ponsável(ROGERS, 1977 em FEITOSA; BRANCO \& VIEIRA, 2017, p. 786).
\end{abstract}

A Abordagem Centrada na Pessoa situou-se enquanto vertente que buscou práticas democráticas, reverberando para espaços educacionais e diferentes contextos de relação coletiva. Perceber todas as pessoas como capazes, responsáveis e autônomas aumenta as possibilidades de se viver relações saudáveis, horizontais e valorizadoras em micro e macrocontextos.

A nomenclatura "não diretiva" foi utilizada nas produções iniciais de Rogers - década de 1940 -, sendo substituída, em 1951, por "centrado em" (MOREIRA, 2010). A autora destaca que, ao longo do tempo, Rogers deslocou seu interesse, pesquisa e atuação do mundo subjetivo do indivíduo para as interações sociais e coletivas. Moreira explica ainda que a ideia de não diretividade teve como objetivo a desconstrução da figura de autoridade do terapeuta e que Rogers, na década seguinte, renuncia a teorias rígidas, encontrando nas condições facilitadoras outra maneira de se lidar com a questão da autoridade. 
Libâneo (2005) discute sobre dois grandes vieses pedagógicos: liberal e progressista. Dentro do primeiro estão as práticas pedagógicas inspiradas no escolanovismo, estando centrada em estudantes, classificada como "pedagogia liberal renovada não diretiva". O autor entende que professoras/es não deveriam fazer qualquer forma de intervenção a fim de se estabelecer um clima adequado para a aprendizagem, com as atitudes facilitadoras da ECE. A função docente é a de facilitador/a dos processos de construção de conhecimento (ROGERS \& KINGET, 1977) o que não o destitui de funções ou o torna obsoleto. Ao contrário, à função docente é extremamente necessária para proporcionar condições adequadas de desenvolvimento, fomentando e mediando os processos vividos dentro e fora de sala de aula.

O pensamento pedagógico liberal é entendido por Libâneo (2005) como manifestação dos interesses do capitalismo. Considera também como tendência não-crítica porque desconsideraria aspectos socio-estruturais da educação e ressaltaria a compreensão de aptidões e formação para desempenho de papéis sociais dentro de uma sociedade de classes. Por mais que a Pedagogia Nova faça um contraponto ao que ele nomeia de Pedagogias Tradicionais ${ }^{1}$, Libâneo considera que acentua os aspectos técnico-pedagógicos por privilegiar o envolvimento afetivo e efetivo de estudantes no lugar de um aparente desenvolvimento cognitivo sem significados próprios. A ACP defende uma aprendizagem significativa (ROGERS \& KINGET, 1977) oportunizando o desenvolvimento de habilidades que permitam uma participação discente ativa nos processos educativos.

De maneira bastante próxima à Libâneo, Becker (2016) argumenta que práticas pedagógicas centradas em estudantes sucateariam a prática docente, pois entende que existe um poder docente relacionado à ação de ensino e que aprendizagem deveria estar subordinada a ela. Essa visão vai de fato entender que professoras/es sejam desempoderadas/os por qualquer prática que entenda estudantes como co-responsáveis e ativos nos processos de construção de conhecimento. Porém cabe aqui questionar sobre quais os perigos em se confiar nas condições e habilidades de estudantes.

Respaldando-se em Althusser, Snyders (1975) defende que o método pelo qual determinado conteúdo é ensinado é subordinado ao conteúdo em si. Assim, todas as práticas oriundas do escolanovismo não seriam um contraponto ao Ensino Convencional porque inovam no método, mas permanecem com conteúdo similar. Para Snyders, a/o professor/a tem a função de introduzir conteúdos específicos visando promover uma formação transformadora da realidade socioeconômica. Para o autor, as pedagogias chamadas por ele de não-diretivas falham nesse

\footnotetext{
${ }^{1}$ E que aqui chamaremos de Educação Convencional por entender que Educação Tradicional se refere às práticas de construção de conhecimentos de povos tradicionais
} 
aspecto pois estudantes não elegeriam certas questões de cunho sociopolítico interessantes, motivadoras e significativas. Questionamos aqui se tal postura não seria, além de autoritária, pouco efetiva, uma vez que, sem interesse ou motivação, as chances de ocorrer um aprendizado de fato ficam reduzidas ou inexistem.

Posturas como esta, que remontam ao paradigma colonialista, são comuns entre as experiências educativas de milhões de alunos ao redor do mundo. Mesmo educadores munidos de boas intenções e do genuíno interesse de transformar a realidade, principalmente em contextos de muita injustiça social como é o caso brasileiro, têm dificuldade de entender que o autoritaris mo na relação professor aluno e o desrespeito aos saberes não hegemônicos (ou do Norte) despotencializam qualquer prática pedagógica bem intencionada e afastam os estudantes da prática política (CASTRO, 2009).

Por isso, entendemos que o paradigma centrado em estudantes atualiza as relações de poder da relação professor aluno sem tirar a importância do papel de facilitador da aprendizagem que o professor tem. E, ao mesmo tempo, sem mantê-lo no lugar do suposto e inquestionável saber. Assim, o professor, como facilitador da aprendizagem significativa, levaria o aprendiz ao saber autônomo a partir de autenticidade e confiança mútuas, fundamentais a qualquer relação de pessoa para pessoa.

\section{Saberes latino-americanos}

Um dado bastante relevante que subsidia a nossa escolha, de encontrar nas práticas e posturas da Educação Centrada em Estudantes contribuições para fazeres pedagógico decolonizadores, é o fato de que existiu, desde o início dos anos oitenta, a busca por uma ACP latinoamericana. Em 1982 foi realizado o I Fórum Internacional da ACP, na cidade de Oaxtepec, México. Durante esse evento, no período da manhã, aconteceram encontros para discutir específica e explicitamente acerca de uma ACP por e para a América Latina (Fonseca, 1994). Nos anos subsequentes até hoje, temos periodicamente eventos latinoamericanos e brasileiros para discutir e produzir a partir de nossos saberes.

Os Fóruns e Encontros brasileiros e latinos da ACP sempre tiveram um caráter não centralizador, sendo o conhecimento produzido, conduzido e organizado por todos os envolvidos. A organização de eventos e compartilhamentos de trabalhos é realizada de forma autogestionária, configurando-se enquanto uma postura epistêmica que rompe com estruturas hierarquizadas, enfatizando-se as relações humanas, a participação coletiva (TASSINARI \& PORTELA, 1998). Na busca por práticas não dominadoras ou colonizadoras em espaços 
acadêmicos é importante que exista uma reestruturação nas formas de pertencimento e atuação dos sujeitos, compromissadas com experiências pautadas no diálogo, no trabalho coletivo e na aprendizagem entre pares (MIRANDA, 2013).

Existe, portanto, desde o início dos eventos internacionais, uma identidade latinoamericana da ACP em constante afirmação e (re)construção. E, além de existir e resistir, ela também colabora para a desconstrução de posturas e entendimentos europeus e estadounidenses. A fase identificada como pós rogeriana abrange diferentes movimentos (MOREIRA, 2010) desenvolvidos a partir de releituras das diferentes fases das produções de Rogers e também com a contribuição de diferentes autores, demonstrando que é uma abordagem dinâmica, não estanque, diversa e que permite o traçado de novos caminhos e possibilidades.

No Brasil, algumas dessas releituras partem de críticas à $\mathrm{ACP}$, entendendo que faltava à teoria original uma visão mais coletiva que atingisse todas as questões e confrontos sociais que as relações humanas e nossos contextos abarcam e promovem. A forma como Rogers entendia os conceitos de liberdade, responsabilidade, individualidade e condições facilitadoras poderiam ser vistas de maneira alienante quando não problematizadas e se fazia necessário "elaborar novas formas de relacionamento mais autêntico, consciente e situado aos problemas sociais do Brasil e aos mecanismos alienantes que atuam sobre a pessoa" (FEITOSA; BRANCO; VIEIRA, 2017, p. 789). Assim, a partir de aportes fenomenológicos e marxistas, iniciou-se na década de oitenta, um movimento que atualizava o legado de Rogers. Tais vieses faziam sentido à época, sendo pertinente um novo percurso, já quase na terceira década deste século, a partir de leituras e críticas atuais.

É o que propomos aqui. Dar início a um novo movimento que entende a validade da teoria original bem como daquelas emergentes no período de redemocratização, mas que as percebe descoladas de nossos contextos, vivências e percepções atuais. Escrevemos este artigo em 2019, ano marcado por retrocessos nos diferentes campos de nossa sociedade, notadamente na educação, com múltiplos mecanismos de controle de práticas, conteúdos e com uma tentativa de aniquilação da produção de conhecimento nas áreas de ciências humanas e sociais. Nesse momento, encontramos a possibilidade de propor uma nova atualização da Abordagem Centrada na Pessoa e suas aplicações nas práticas educacionais, o que chamamos de Educação Centrada em Estudantes. Mais do que falar de um Ensino Centrado em Estudantes ou em uma Aprendizagem Centrada em Estudantes, nomenclaturas comumente utilizadas por Rogers e por outras publicações acerca do tema, queremos pensar na Educação como um todo. A educação não se reduz a processos de ensinar e aprender. Ela engloba relações, posturas e visões de 
mundo. Queremos cunhar a Educação Centrada em Estudantes como um novo paradigma decolonial na educação.

\section{Educação centrada em estudantes e práticas decoloniais}

As práticas pedagógicas próprias da Educação Convencional estão relacionadas à colonização epistemológica. Os saberes validados são oriundos de um recorte geopolítico específico, respaldados por um privilé gio epistêmico e obtido através de métodos considerados científicos por serem imparciais, replicáveis e controlados dentro de uma perspectiva positivista e cartesiana São diversos os mecanismos de controle empregados para garantir uma subalternização de estudantes e também docentes a uma macroestrutura: desde uma homogeneização de práticas pedagógicas facilmente replicáveis em larga escala (inclusive pela tecnologia moderna) até retirar a possibilidade de construção de saberes próprios e coletivos.

Encontramos na ECE que desenhamos neste estudo possibilidades de rupturas na estrutura epistemológica, entendendo-a como uma abordagem emergente que apresenta interfaces com um pensamento decolonial. Tais questões correlatas estão, a nosso ver, relacionadas as três condições necessárias em um clima facilitador de crescimento, bem como a compreensão de Tendência Atualizante, que fazem parte do arcabouço teórico-prático da ACP.

As condições facilitadoras devem existir nas relações entre estudantes e docentes, ocasionando uma mudança nas posturas comumente existentes nos espaços educacionais. É fundamental destacar que apesar da ACP e, consequentemente a ECE, pode ser interpretada enquanto meritocrática, ao perceber as pessoas como plenas de potencialidades e possibilidades. Isso não significa que depende apenas do sujeito qualquer realização ou conquista. Tal percepção ignoraria todo um contexto opressor e proibitivo que várias pessoas vivem a partir das práticas colonizadoras e territórios colonizados.

É importante promover um espaço de construção coletiva de conhecimentos que possibilite de fato à pessoa acessar e exercer suas potencialidades para operar mudanças, A narrativa de uma experiência de construção de conhecimentos por estudantes do curso de Psicologia, enfatizando a busca por aprendizagens significativas. Vieira e colaboradores (2018) mostram uma possibilidade de tais práticas. Neste artigo, estudantes, cumprindo estágio clínico final em ACP, registram suas percepções após cada atendimento, ultrapassando descrições puramente acadêmicas e dando vazão a compreensões e produzindo conhecimentos próprios que serão levados para o espaço de supervisão. Estudantes são reconhecidos enquanto sujeitos 
produtores de conhecimentos e capazes de contribuir para sua própria formação e seus colegas também.

Walsh (2013) se remete a Fanon para explicar que a decolonização é uma forma de desaprendizagem, afinal, faz-se necessário desaprender tudo aquilo que foi imposto pela colonização e desumanização e assumido como único conhecimento adequado. E, além disso, empreender um processo de reaprendizagem sobre se constituir sujeitos. Quando pensamos no contexto educacional e, mais especificamente, na Educação Superior enquanto lócus de manutenção das estruturas de saber e poder, temos a concepção de engaged scholarship como proposta de práticas de ensino e pesquisa que conectam a universidade à comunidade, tendo dois valores centrais: a justiça social e a cidadania (BEAULIEU; BRETON; BROUSSELLE, 2018).

Partindo da compreensão de que comunidade inclui estudantes da universidade enquanto sujeitos pensantes e produtores de conhecimentos, encontramos nesta perspectiva mais um subsídio para a defesa da ECE conforme prática didático-pedagógica na Educação Superior. Como manter-se coerente a uma proposta de conexão com a comunidade em geral se não há conexão com a comunidade acadêmica em situações básicas como o envolvimento ativo de todas as pessoas que constituem um curso? Dinâmicas mais horizontalizadas no contexto acadêmico colaboram para a promoção da justiça social e cidadania por promoverem uma noção de concepção e prática de sujeitos plenos e potentes. A engaged scholarship é um ato decolonial, que transforma espaços e relações Schultz (2013). Da mesma forma como é fundamental ouvir um indígena falando sobre sua própria vivência e de seu povo, ouvir de estudantes sobre seus modos de produzir conhecimento também é essencial para produzirmos e praticarmos sobre educação.

Ao falar sobre as concepções e práticas pedagógicas de Paulo Freire, Franz Fanon e outros que buscaram transgredir, deslocar e negar o poder e a colonialidade em algum grau, Walsh (2013) explica que

Más que "incluir" de manera multiculturalista, el esfuerzo ha sido de construir, posicionar y procrear pedagogías que apuntan el pensar "desde" y "con", alentando procesos y prácticas "praxísticas" de teorización - del pensar-hacer- e interculturalización que radicalmente desafían las pretensiones teórico-conceptuales y metodológicas-académicas, incluyendo sus supuestos de objetividad, neutralidad, distanciamiento y rigor. Pedagogías que se esfuerzan por abrir grietas y provocar aprendizajes, desaprendizajes y reaprendizajes desprendimientos y nuevos enganchamientos; pedagogías que pretenden plantar semillas no dogmas o doctrinas, aclarar y en-redar caminos, y hacer andar horizontes de teorizar, pensar, hacer, ser, estar, sentir, mirar y escuchar - de modo individual y colectivo - hacia lo decolonial. (WALSH, 2013, p. 66) 
Entendemos que os atos de teorizar, pensar, fazer, ser, estar, sentir, olhar e escutar em espaços coletivos de construção de conhecimento são promovidos, valorizados e acolhidos da Educação Centrada em Estudantes a partir das atitudes facilitadoras. A empatia, a autenticidade e a consideração positiva incondicional em contextos educacionais podem abrir caminhos para um percurso decolonial.

\section{Traçados transconectados}

$\mathrm{Na}$ parte final deste artigo, traçamos paralelos entre alguns conceitos/ compreensões decoloniais e a Abordagem Centrada na Pessoa - em específico, a Educação Centrada em Estudantes (ECE), buscando aproximar estas duas epistemologias, vista por muitos teóricos como inconciliáveis, porém apresentada neste trabalho como possibilidade de consolidação de práticas educacionais democráticas, libertárias e decolonizadas.

É bastante frequente nas discussões decoloniais a alusão a processos sistêmicos de violência simbólica. Fanon já trazia a ideia de que as práticas coloniais esvaziam o sujeito até que esse sinta que nada sabe e que depende do outro (FANON, 1979). Estudantes passam por todo o percurso educacional vivendo em situação de opressão, considerados incapazes, destituídos de potencialidades. A ACP, com a compreensão da Tendência Atualizante, vai justamente dizer que são todos capazes, interessados e com potencial para a constante evolução.

É importante frisar que professoras e professores também são oprimidos e coloniza dos. Para além do sistema como um todo, a própria formação os coloca nesse lugar formatado e de lá seguem aceitando e naturalizando práticas e situações violentas. Entender cada sujeito, seja ele uma criança da Educação Fundamental ou um/a educador/a em formação continuada, enquanto pessoa que quer aprender e consegue se desenvolver sem laços de dependência com quem detém o conhecimento, é uma postura que não permite atos de violência simbólica em relação a saberes.

A defesa pela autodeterminação de povos e territórios enquanto direito de autodeterminação e soberania pode ser entendida como uma ampliação do que a ACP traz em sentido individual. A autonomia e o envolvimento ativo da pessoa em seus processos - sejam terapêuticos ou educacionais - é condição fundamental para aprendizagens. A ECE promoverá condições para que estudantes definam seus objetivos, tracem percursos e os percorram de maneira autônoma, podendo ser considerada uma forma de autogovernabilidade. Em um paralelo estabelecido por Santiago (2018), a escrita de mulheres negras pode ser compreendida enquanto um exercício de autogovernabilidade e de empoderamento, uma vez que quebra um 
processo de apagamento de suas vozes, justamente por meio de uma prática de autonomia e envolvimento ativo em seu processo de (re)existência.

Nos processos de construção de conhecimento, a presença da pessoa facilitadora de aprendizagens não deixa de existir, porém aparece na forma de mediadora, permanecendo o protagonismo da/o estudante. Em nosso contexto extremamente colonizado/colonizante, não se ouvem ou se respeitam os saberes oriundos de pessoas que se situam abaixo de uma linha constituída hierarquicamente.

De povos tradicionais a mulheres ou crianças, são diversos os países, grupos e pessoas desacreditados por não atenderem determinados requisitos ou padrões impostos há séculos pelos colonizadores/ capitalistas/ classes e culturas hegemônicas. Dessa forma, entendemos que as condições facilitadoras para o crescimento no meio educacional são posturas de não negação e, mais do que isso, de escuta, respeito e valorização do Outro.

\section{Referências}

BEAULIEU, M., BRETON M., BROUSSELLE, A. Conceptualizing 20 years of engaged scholarship: A scoping review. PLoS ONE, v. 13, n. 2, p. 193-201, 2018. Disponível em: https//journals.plos.org/plosone/article? $\mathrm{id}=10.1371$ /journal.pone.0193201. Acesso em: $20 \mathrm{de}$ abril de 2020.

BECKER, F. Educação e construção do conhecimento revista e ampliada. Porto Alegre: Penso, 2016.

BERNARDINO-COSTA, J. \& GROSFOGUEL, R. Decolonialidade e perspectiva negra. Sociedade e Estado, v. 31, n. 1, p. 15-24, 2016. Disponível em: http://www.scielo.br/pdf/se/v31 n1/0102-6992-se-31-01-00015.pdf. Acesso em 16 de abril de 2020.

BOAINAIN, E. JR. Tornar-se transpessoal: transcendência e espiritualidade na obra de Carl Rogers. São Paulo: Summus, 1998.

FANON, F. Os condenados da terra. Rio de Janeiro: Civilização Brasileira, 1979.

FEITOSA, E. A. L., BRANCO, P. C. C., \& VIEIRA, E. M. Notas sobre a visita de Carl Rogers ao Brasil: uma revolução silenciosa. Estudos e Pesquisas em Psicologia, v. 17, n. 2, p. 777795, 2017. Disponível em: http:/pepsic.bvsalud.org/pdf/epp/v17n2/v17n2a20.pdf. Acesso em 16 de abril de 2020.

FONSECA, A. L. De Oaxtapec ao Nordeste da América do Sul: O Encontro Latino Americano da Abordagem Centrada na Pessoa, 1994. 
GROSFOGUEL, R. A estrutura do conhecimento nas universidades ocidentalizadas: racismo/sexismo epistêmico e os quatro genocídios/epistemicídios do longo século XVI. Sociedade e Estado, v. 31, n. 1, p. 25-49, 2016. Disponível em: http://www.scielo.br/pdf/se/v31 n1/0102-6992-se-31-01-00025.pdf. Acesso em 16 de abril de 2020.

LIBÂNEO, J. C. Democratização da escola pública: a pedagogia crítico social dos conteúdos. São Paulo: Loyola, 2005.

Histórias locais / projetos globais: colonialidade, saberes subalternos e pensamento liminar. Belo Horizonte: Editora da UFMG, 2003.

MIGNOLO, W. El pensamiento decolonial: desprendimiento y apertura. Un manifiesto. In. CASTRO-GÓMEZ, S.; GROSFOGUEL, R. (Orgs.). El giro decolonial: reflexiones para una diversidad epistémica más allá del capitalismo global. Bogotá: Siglo del Hombre Editores, 2008, p. 25-46.

MIRANDA, C. Presentación. In: WALSH, C. (Org). Pedagogías decoloniales: prácticas insurgentes de resistir, (re)existir y (re)vivir. Tomo I. Quito, Ecuador: Ediciones Abya-Yala, 2013.

MOREIRA, V. Revisitando as fases da abordagem centrada na pessoa. Estudos de Psicologia (Campinas), v. 27 n.4, p. 537-544, 2010. Disponível

em:http://www.scielo.br/pdf/estpsi/v27n4/11.pdf. Acesso em 16 de abril de 2020.

OLIVEIRA, L. F. O que é uma educação decolonial. Nuevamérica (Buenos Aires), n. 149, p. 35-39, 2016.

ROGERS, C. R. \& KINGET, G. M. Psicoterapia e Relações Humanas, v. 1, Belo Horizonte: Interlivros, 1977.

ROGERS, C.R. Liberdade e aprender em nossa década. Porto Alegre: Artes Médicas, 1985.

ROGERS, C. R. \& ROSENBERG, R. L. A Pessoa como centro. São Paulo, SP: Editora Pedagógica e Universitária, 1997.

ROGERS, C.R. E WOOD, J.K. Teoria Centrada no Cliente: Carl Rogers. In: BURTON, A. (Org.). Teorias Operacionais da Personalidade. Rio de Janeiro: Imago, 1974, p. 192 - 233. SANTIAGO, A. R. Memórias poéticas de autoras negras: reinvenções de (re)existências. Itinerários, n. 46, p. 35-50, 2018. Disponível em: https $/ /$ periodicos.fclar.unesp.br/itinerario s/article/view/10859/7991. Acesso em 16 de abril de 2020.

SHULTZ, L. Engaged Scholarship in a Time of the Corporatization of the University and Distrust of the Public Sphere: A Decolonizing Response. In: SHULTZ, L. \& KAJNER, T. (Orgs). Engaged Scholarship: The Politics of Engagement and Disengagement. Rotterdam: Sense Publishers, 2013, p. 43 - 54.

SPIEGELBERG, H. Phenomenology in Psychology and Psychiatry. Evanston, IL: Northwestern University Press, 1972. 
TASSINARI, M. \& PORTELA, Y. História da Abordagem Centrada na Pessoa no Brasil. In: GOBBI, S.; MISSEL, S. (Org.). Abordagem Centrada na Pessoa: vocabulário e noções básicas. Tubarão: Ed. Universitária UNISUL, 1998, p. 227 - 260.

VIEIRA, E. M., BEZERRA, E. DO N., PINHEIRO, F. P. H. A. \& BRANCO, P. C. C. Versão de sentido na supervisão clínica centrada na pessoa: alteridade, presença e relação terapêutica. Revista Psicologia e Saúde, v. 10, n. 1, p. 63-76, 2018. Disponível em: http://pepsic.bvsalud.org/pdf/rpsaude/v10n1/v10n1a05.pdf. Acesso em: 16 de abril de 2020.

WALSH, C. Pedagogías decoloniales: prácticas insurgentes de resistir, (re)existir y (re)vivir. Tomo I. Quito, Ecuador: Ediciones Abya-Yala, 2013. 